\title{
Characterization of sodium alginate/D-limonene emulsions and respective calcium alginate/D-limonene beads produced by electrostatic extrusion
}

\author{
Steva Lević a, Ivana Pajić Lijaković ${ }^{\mathrm{b}}$, Verica Đorđević ${ }^{\mathrm{b}}$, Vladislav Rac ${ }^{\mathrm{a}}$, Vesna Rakić a \\ Tatjana Šolević Knudsen ${ }^{c}$, Vladimir Pavlović ${ }^{a}$, Branko Bugarski ${ }^{\text {b }}$, Viktor Nedović ${ }^{\text {a, * }}$ \\ ${ }^{a}$ University of Belgrade-Faculty of Agriculture, Nemanjina 6, 11081 Belgrade-Zemun, Serbia \\ b University of Belgrade-Faculty of Technology and Metallurgy, Karnegijeva 4, 11000 Belgrade, Serbia

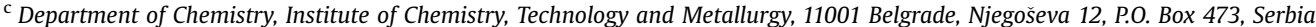

\section{A R T I C L E I N F O}

Article history:

Received 18 April 2014

Accepted 1 October 2014

Available online 8 November 2014

\section{Keywords:}

Immobilization

Alginate

Electrostatic extrusion

D-limonene

Swelling

\begin{abstract}
A B S T R A C T
In this study, calcium alginate beads immobilizing D-limonene (solid systems) have been manufactured starting from emulsions of this flavor in sodium alginate (liquid systems). The effects of alginate concentration $(0.02$ and $0.03 \mathrm{~g} / \mathrm{mL}$ ) and flavor content ( 5 and $10 \% \mathrm{w} / \mathrm{w})$ on viscosity, conductivity and stability of emulsions were investigated. The flavor droplets in emulsions are bigger as polymer solution is more concentrated and contains more of the flavor. When emulsions have been subjected to electrostatic extrusion and upon $\mathrm{Na}^{+}-\mathrm{Ca}^{2+}$ ion exchange, smaller $(\sim 960$ to $\sim 1450 \mu \mathrm{m})$ and less spherical beads were obtained (sphericity factor $0.003-0.21$ ) compared to beads produced by simple dripping technique (without electrostatic field). When wet beads were air dried, they shrunk less if they had higher content of the flavor. Novel mathematical model describing swelling kinetics of dried beads is developed. In this work, D-limonene was efficiently immobilized within Ca-alginate beads (immobilization efficiency $~ 50$ to 77\%) and its thermal stability was confirmed by TG/MS analysis.
\end{abstract}

(c) 2014 Elsevier Ltd. All rights reserved.

\section{Introduction}

D-limonene is the major flavor compound of citrus oil and it has been widely used as a food flavor (Burdock, 2004; Sahraoui, Abert Vian, El Maataoui, Boutekedjiret, \& Chemat, 2011) and medicament for tumor treatment (Del Toro-Arreola et al., 2005; Nakaizumi, Baba, Uehara, Iishi, \& Tatsuta, 1997; Uedo et al., 1999). Nevertheless, it has highly lipophilic nature which results in poor absorption and palatability. Besides, limonene is susceptible to oxidative degradation and this results in the loss of lemon-like flavor under normal storage condition (Soottitantawat, Yoshii, Furuta, Ohkawara, \& Linko, 2003). Aroma such is limonene can be encapsulated in order to improve its functionality and stability in products. Apart from protection at ambient conditions (air humidity, oxygen, etc.), encapsulation should provide thermal protection during food processing. Another possible benefit of aroma's encapsulation is superior ease of handling, as conversion of liquid aroma oil into a powder is achieved. Various

\footnotetext{
* Corresponding author. Tel./fax: +381 112199711

E-mail address: vnedovic@agrif.bg.ac.rs (V. Nedović).
}

encapsulation methods have been previously proposed for encapsulation of liquid aromas such as limonene. Among them, spray-drying is the most popular method of producing flavor powders (Soottitantawat et al., 2005; Zuidam \& Heinrich, 2010). However, it is rather difficult to remove water by vaporization while retaining the flavors that are much more volatile than water (Soottitantawat et al., 2003), and a lot of effort has to be invested in preventing flavor losses during spray-drying. Instead, extrusion/ dropping techniques provide simple and safe processing for production of microspheres as biopolymer gel microbeads embedding oil droplets. Moreover, extrusion techniques have advantage when bigger particles $(100-1000 \mu \mathrm{m}$ in contrast to small size $10-150 \mu \mathrm{m}$ spray-dried aroma powders) are needed in order to create special visible or textural effects (for example in crunchy food products). Among extrusion techniques, electrostatic extrusion is the one suitable for processing polymer solutions in the wide range of viscosities and production of particles of desired and uniform size (Prüsse et al., 2008). It is based on the use of electrostatic forces to disrupt the liquid filament at the tip of a needle and to create a charged stream of small droplets. The excessive investigations were performed to determine the specific influence of each of the processing parameters on the diameter of microbeads (Bugarski, 
Obradovic, Nedovic, \& Goosen, 2006). In this study, calcium alginate gel was employed as the matrix for D-limonene immobilization, as it has been determined that calcium-alginate does not adversely affect the release of the flavor during consumption (De Roos, 2003; 2006). Also, alginate gel beads are suitable for application in food products as they showed good properties during gastro-intestinal evaluations (Rayment et al., 2009). One of the critical points of the encapsulation of lipophilic flavors is low stability of alginate-flavor emulsions. In order to conquer the instability induced by the high hydrophilicity of alginate particles several strategies have been proposed, such as addition of conventional surfactants (You, Rafat, \& Auguste, 2011) and coating with chitosan to modify the hydrophilicity of alginate particles (Nan et al., 2014). However, the addition of any of this compounds inevitable increases costs, furthermore, the usage of surfactants is limited in food applications and it unavoidably results in low biocompatibility of alginate particles. Therefore, in this work we tried to immobilize a flavor compound in alginate microspheres by internal gelation in the absence of surfactants, so that the flavor is only roughly stabilized by developed viscosity of alginate in aqueous systems.

The objective of the present study is to investigate the characteristics of alginate as a matrix material for immobilization of the liquid flavor such as D-limonene. We intend to reveal the interdependence of characteristics (such as viscosity, conductivity, stability and flavor droplet size distribution) of $\mathrm{Na}$-alginate/D-limonene emulsions (liquid systems) with the properties of the corresponding Ca-alginate/D-limonene beads (solid systems) produced by electrostatic extrusion technique. Thus, the effects of immobilization process on the flavor's physical and thermal stabilities were examined. For assessment of the thermal stability, the immobilized flavor is tested by thermogravimetric/mass spectrometry analysis. Beside hydrogel beads, dried forms of those were also investigated as they are stronger than non-dried hydrogel beads and more convenient for long shelf life products. Rehydration of air-dried beads was examined in detail, as controlled rehydratability is important to many food applications (e.g. preparations of instant products).

\section{Materials and methods}

\subsection{Chemicals}

D-limonene was obtained from HiMedia Laboratories Pvt.Ltd (Mumbai, India). Sodium alginate (from Macrocystis pyrifera, molecular weight: $80,000-120,000$. M/G ratio: 1.56 ) was purchased from Sigma (St. Louis, USA). Calcium chloride dihydrate was purchased from Acros Organics (New Jersey, USA), while n-hexane (HPLC grade) was suplied from Carlo Erba Reagenti SpA (Rodano, Italy). All other chemicals were of analytical reagent grade and they were used without any further purification.

\subsection{Preparation and characterization of the liquid systems}

The preparation of liquid systems was the first step of immobilization process. The liquid systems used in this study were water solutions of Na-alginate (concentration of $0.02 \mathrm{~g} / \mathrm{mL}$ or $0.03 \mathrm{~g} / \mathrm{mL}$ ) and $\mathrm{Na}$-alginate/D-limonene emulsions $(5 \% \mathrm{w} / \mathrm{w}$ or $10 \% \mathrm{w} / \mathrm{w}$ of dispersed $\mathrm{D}$-limonene in $0.02 \mathrm{~g} / \mathrm{mL}$ or $0.03 \mathrm{~g} / \mathrm{mL}$ Na-alginate). The compositions of the liquid systems which are denoted as $S_{a}^{b}$ (where $a$ is the concentration of Na-alginate (in $\mathrm{g} / \mathrm{mL}$ ) while $b$ is D-limonene concentration in $\% \mathrm{w} / \mathrm{w}$ ) and used in this study are summarized in Table 1.
Table 1

The composition of the liquid systems used for immobilization process.

\begin{tabular}{lllll}
\hline $\begin{array}{l}\text { Formulation } \\
\text { no. }\end{array}$ & Sample & $\begin{array}{l}\text { Na-alginate } \\
\text { concentration } \\
(\mathrm{g} / \mathrm{mL})\end{array}$ & $\begin{array}{l}\text { D-limonene } \\
\text { concentration } \\
(\% \mathrm{w} / \mathrm{w})\end{array}$ & $\begin{array}{l}\text { Applied } \\
\text { voltage }(\mathrm{kV})\end{array}$ \\
\hline 1 & $S_{0.02}^{0}$ & 0.02 & 0 & 0 \\
2 & $S_{0.03}^{0}$ & 0.03 & 0 & 0 \\
3 & $S_{0.02}^{5}$ & 0.02 & 5 & 0 \\
4 & $S_{0.03}^{5}$ & 0.03 & 5 & 0 \\
5 & $S_{0.02}^{10}$ & 0.02 & 10 & 0 \\
6 & $S_{0.03}^{10}$ & 0.03 & 10 & 0 \\
7 & $S_{0.02}^{0}$ & 0.02 & 0 & 6.5 \\
8 & $S_{0.03}^{0}$ & 0.03 & 0 & 6.5 \\
9 & $S_{0.02}^{5}$ & 0.02 & 5 & 6.5 \\
10 & $S_{0.03}^{5}$ & 0.03 & 5 & 6.5 \\
11 & $S_{0.02}^{10}$ & 0.02 & 10 & 6.5 \\
12 & $S_{0.03}^{10}$ & 0.03 & 10 & \\
\hline
\end{tabular}

\subsection{Preparation of D-limonene/Na-alginate emulsions}

D-limonene was added into the Na-alginate solutions under vigorous mixing at $10.000 \mathrm{rpm}$ for 5 min using mechanical stirrer Ultra-Turrax $^{\circledR}$ T25 (Janke and Kunkel Ika-Labortechnik, Staufen, Germany).

\subsection{Measurements of rheological features of liquid systems}

Viscosity measurements (in triplicate) were carried out using a viscometer (Rheotest 2, MLW, OT Medingen, Ottendorf-Okrilla, Germany) in the range of the shear rate from 0 to $1300 \mathrm{~s}^{-1}$ during $7 \mathrm{~min}$. The cylinder measuring configuration was S/S1 which has the viscosity range between 20 and $10^{5} \mathrm{mPa}$. The experimental results were fitted with Power law model:

$\tau=k \times \dot{\gamma}^{n}$

and consistency $(k)$, and flow index $(n)$ were determined. In power law equation, $\tau$ is the shear stress and $\dot{\gamma}$ is the shear rate.

The thixotropic properties of the liquid samples were characterized by using hysterics experiments which consisted of a three step operation (upward curve, plateau curve and downward curve): an increasing shear rate ramp at a constant shear rate of $3.10 \mathrm{~s}^{-1}$ from 0 to $1300 \mathrm{~s}^{-1}$, followed by a plateau at the maximum shear rate for $50 \mathrm{~s}$, and thereafter, the ramp was reversed (with the same rate) to measure downward flow curve from 1300 to $0 \mathrm{~s}^{-1}$. For timedependent samples, the area enclosed between up curves and down curves obtained by increasing and decreasing shear rate measurements was calculated as the difference between integrating the area for forward and backward measurements from $\dot{\gamma}_{1}$ (initial shear rate) to $\dot{\gamma}_{2}$ (final shear rate):

Hysteresis loop area $=\int_{\dot{\gamma}_{1}}^{\dot{\gamma}_{2}} k \dot{\gamma}^{n}-\int_{\dot{\gamma}_{1}}^{\dot{\gamma}_{2}} k^{\prime} \dot{\gamma}^{n^{\prime}}$

Where $k, k^{\prime}$, and $n, n^{\prime}$ are the consistency coefficient and flow index behavior for forward and backward measurements, respectively.

\subsection{Conductivity of the liquid systems}

The conductivities of the solutions and the emulsions were measured (in triplicate) using conductometer InoLab ${ }^{\circledR} 720$ (WTW $\mathrm{GmbH}$, Weilheim, Germany), at room temperature. 


\subsection{Stability of the emulsions}

Stability of the emulsions was tested by applying the procedure reported by Chan (2011). Briefly, $\sim 50 \mathrm{~mL}$ of an alginate-flavor emulsion was left to stand for $1 \mathrm{~h}$ in order to investigate emulsion stability. The volume of phases which had been formed during the period of $1 \mathrm{~h}$ was measured (in triplicate). Emulsion stability was calculated as a quotient of the volume of the remaining emulsion and volume of the initial emulsion and expressed in \%.

\subsection{D-limonene droplet size measurements}

The flavor droplet size of the each of D-limonene/Na-alginate emulsion formulations was determined as a numeric average of 100 droplets which diameters were measured under an optical microscope (Olympus CX41RF, Tokyo, Japan) equipped with a camera (Olympus U-CMAD3, Tokyo, Japan) and coupled with the image analysis program "Cell ${ }^{A}$ " (Olympus, Tokyo, Japan).

\subsection{Preparation and characterization of the solid systems}

The solid systems were produced by the procedure developed previously by Nedović et al. (2001) and Levic et al. (2013). The schematic presentation of the immobilization process is shown in Fig. 1a. Electrostatic immobilization unit (VAR V1, Nisco Engineering Inc., Zurich, Switzerland) used in this work is a compact system equipped with a high voltage unit, magnetic stirrer and protective cage. Spherical droplets were formed by extrusion of the liquid systems through a blunt stainless steel needle using a syringe pump (Pump 11, Harvard Apparatus, Holliston, US). The needle was grounded, while the collecting solution $\left(\mathrm{CaCl}_{2}\right.$ in water solution with a concentration of $0.015 \mathrm{~g} / \mathrm{mL}$ ) was positively charged. All samples (Table 1) were extruded simply by dripping without applying any voltage (formulations no. $1-6$ ), and the samples with the same compositions were extruded in the electrostatic field maintained with a constant voltage of $6.5 \mathrm{kV}$ (formulations no. 7-12). Formations of liquid drops during extrusion are shown in Fig. 1b (Fig. 1 $b_{1}$-formation of liquid drops without electrostatic force; Fig. $1 b_{2}$-formation of liquid drops by electrostatic force). The distance between the needle tip (22 gauges) and the collecting solution was $2.5 \mathrm{~cm}$, while the flow rate of the liquid systems was $70 \mathrm{~mL} / \mathrm{h}$. After formation of the beads, they were left in hardening solution without stirring for $60 \mathrm{~min}$ in order to assure finishing of the gelling process. The formed alginate beads were removed from the $\mathrm{CaCl}_{2}$ solution by filtration and washed with distillated water. In this way hydrogel beads were obtained. In order to produce dried forms of beads, hydrogel beads were air-dried at $25^{\circ} \mathrm{C}$ for $48 \mathrm{~h}$.

\subsection{Analysis of the beads dimensions and shape}

Dimensions and shape of hydrogel and dried beads were evaluated by binocular microscope Leica XTL-3 400D (Leica, Wetzlar, Germany), equipped with a camera (DC 300, Leica, Wetzlar, Germany) and software for measuring (IM 1000, Leica, Wetzlar, Germany). For each formulation, a numeric average of average diameters of 100 beads was taken as a mean diameter, whereas the diameter for each bead was calculated as an average of the largest dimension $\left(d_{\max }\right)$ and the smallest dimension $\left(d_{\min }\right)$ perpendicular to the largest diameter of the microbead.

The deformation of the beads from regular spherical shape was calculated and represented as Sphericity factor (SF). Sphericity factor was calculated as described by Chan, Lee, Ravindra, and Poncelet (2009). Briefly, the beads diameters were measured as described above and Sphericity factor was calculated by using Equation (3):

Sphericity factor $(S F)=\frac{d_{\max }-d_{\min }}{d_{\max }+d_{\min }}$

where $d_{\max }$ is the maximum diameter and $d_{\min }$ is the minimum diameter of the beads perpendicular to $d_{\max }$.

The reduction in the beads size after drying was expressed by Shrinkage factor $\left(k_{S F(\text { drying })}\right)$ and calculated according the Equation (4) (Chan et al., 2011):

$k_{S F(\text { drying })}=\left(d_{b}-d_{b(\text { dry beads })}\right) / d_{b}$

where $d_{b}$ was the diameter of the wet beads and $d_{b(d r y ~ b e a d s)}$ was the diameter of the beads after drying.

\subsection{Scanning electron microscopy (SEM)}

The microstructure of samples has been carried out by JEOL JSM6390LV scanning electron microscope. Prior to the analysis the samples were covered with Au using a sputter coater Baltec scd 005 accessory.

\subsection{D-limonene content determination}

Half a gram of the dried beads was dissolved in $40 \mathrm{~mL}$ of sodium citrate $(0.015 \mathrm{~g} / \mathrm{mL})$ in glass bottles and $5 \mathrm{~mL}$ of hexane was added. The flavor was extracted with hexane by heating the samples in glass bottles at $45^{\circ} \mathrm{C}$ in a water bath for $15 \mathrm{~min}$ with intermittent mixing. The samples were then cooled down to room temperature and hexane was separated from the aqueous phase by centrifugation at $4000 \mathrm{rpm}$ for $20 \mathrm{~min}$. The content of D-limonene in the

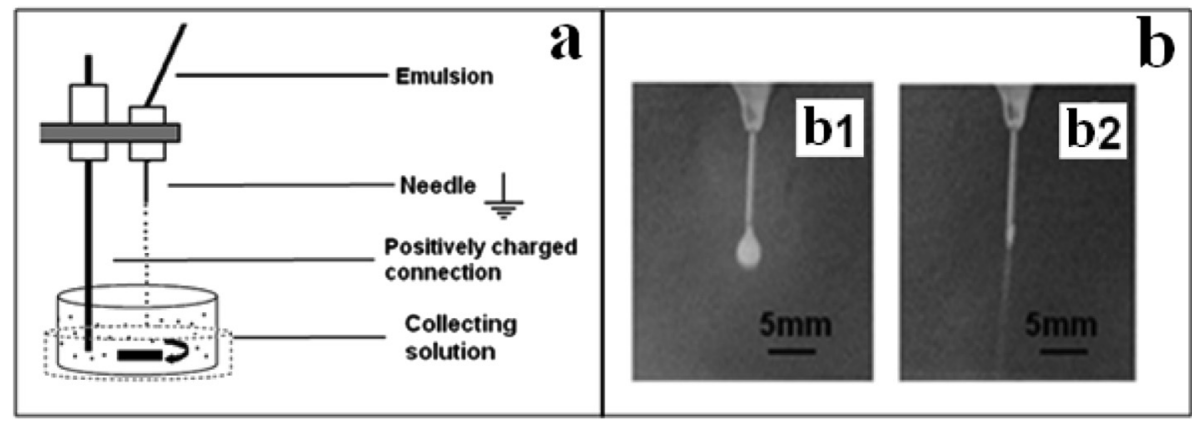

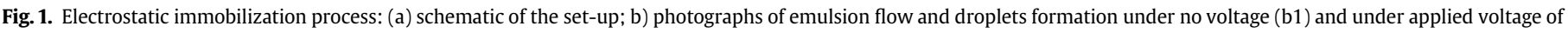
$6.5 \mathrm{kV}(\mathrm{b} 2)$. 
samples was determined by gas-chromatography and calculated from the standard calibration curve. Quantitative analysis was conducted using an Agilent 4890D gas chromatograph fitted with an HP-5MS $30 \mathrm{~m} \times 0.25 \mathrm{~mm}$ capillary column, with hydrogen as the carrier gas (constant flow rate of $1 \mathrm{~cm}^{3} \mathrm{~min}^{-1}$ ) and flameionization detector (FID). The temperature program was: $40{ }^{\circ} \mathrm{C}$ for $9 \mathrm{~min}$; then $15{ }^{\circ} \mathrm{C} \mathrm{min}^{-1}$ to $150{ }^{\circ} \mathrm{C}$ and held for $2 \mathrm{~min}$. The temperatures of the injector and the detector were maintained during the analysis at 250 and $300{ }^{\circ} \mathrm{C}$, respectively. The calibration curve was obtained using seven standard D-limonene solutions which were analyzed under the same conditions as the samples. Data acquisition was performed by GC Chem Station software.

Immobilization efficiency $(E)$ was calculated on the basis of Equation (5):

$E=m_{e} / m_{i} \times 100 \%$

where ${ }_{m e}$ is the mass of encapsulated D-limonene and ${ }_{m i}$ is the initial mass of the flavor.

All samples were analyzed in duplicate and the data were presented as average values \pm standard deviation values (SD).

\subsection{The study of beads swelling}

Swelling studies of the dried Ca-alginate beads (with and without the flavor) were carried out in two different swelling solutions: (1) distilled water and (2) phosphate buffer $(10 \mathrm{mM}, \mathrm{pH}$ 7.4). The weighed amount of the dried beads was immersed in $20 \mathrm{~mL}$ of the swelling solution at room temperature under shaking at $100 \mathrm{rpm}$. At previously defined time intervals, the beads were separated from the swelling solution, gently wiped with filter paper and weighed. The swelling ratio $\left(M_{t}\right)$ of the beads was calculated according to the Equation (6):

$M(t)=\left(w_{1}-w_{2}\right) / w_{2}$

where $w_{1}$ was the weight of the beads in the swollen state and $w_{2}$ was the initial weight of the dried beads.

\subsection{Thermal analysis of the dried beads}

Thermal analysis of samples was carried out in a Setaram's TG/ DSC111 apparatus coupled with mass spectrometer (Thermostar from Pfeifer, system equipped with a capillary connection). The measurements were realized employing the simultaneous thermogravimetry/mass spectrometry (TG/MS) technique under dynamic helium of a flow rate of $30 \mathrm{~mL} / \mathrm{min}$ (pressure $1 \mathrm{~atm}$ ) using a heating rate of $5{ }^{\circ} \mathrm{C} / \mathrm{min}$. The targeted mass spectra (i.e. water, Dlimonene) were selected according to data from the Spectral Database for Organic Compounds, AIST (SDBS).

\subsection{Data analysis}

D-limonene droplet size as well as beads dimension were analyzed using the statistical package PSS 17.0 (SPSS Inc., Chicago, IL, USA). The obtained results were subjected to one-way analysis of variances (ANOVA) in order to determine the differences between multiple means in continuous variables. Statistical significance was set at $p<0.001$. The means are further analyzed with Tukey's HSD test, to find those that differ. Eta-squared $\left(\eta^{2}\right)$ was a measure of effect size, ranging from 0 to 1 .

\section{Results and discussion}

\subsection{Characteristics of the liquid systems}

The properties of the liquid samples (Table 2) were examined as they play important roles in droplet formation upon processing of liquids by extrusion-dripping technique under electrostatic field.

Viscosities of all liquid samples (liquid formulations presented in Table 1) were determined in the range of shear rate from 0 to $1300 \mathrm{~s}^{-1}$. As shown in Fig. 2, the viscosity decreased with the increasing of shear rate for all liquid systems indicating shear thinning behavior. It can be inferred that this behavior of alginate probably originate from conformational changes and orientation of rigid polysaccharide alginate chains in the flow field, what is in accordance with the published data (Lee, Bouhadir, \& Mooney, 2002), which demonstrate that alginate's rigid chain conformation affects mechanical properties of this polysaccharide. Shear viscosity of Na-alginate solutions and Na-alginate $\mathrm{D} /$ limonene emulsions increased with increasing the alginate concentration. This is a result of more intensive chain-chain interactions existing in the more concentrated solutions that express more pronounced non-Newtonian behavior (Manojlović, Đonlagić, Obradović, Nedović, \& Bugarski, 2006). The parameters of the Power law model are presented in Table 2 . The flow index $(n)$ varies from 0.51 to 0.63 , which confirms the shear thinning behavior. Moreover, an increase in the sodium alginate concentration (from 2 to $3 \% \mathrm{w} / \mathrm{v}$ ) at the same concentration of aroma confirmed an increase in the shear thinning which showed a decrease in the flow behavior index $(n)$. The consistency coefficient $(k)$ increased with the concentration of sodium alginate, which is in accordance to literature (Ma, Lin, Chen, Zhao, \& Zhang, 2014; Oliveira et al., 2010). At the same time, higher concentration of the flavor within Na-alginate caused slightly higher values of the viscosity; consequently, $k$ values become higher with increasing the flavor content. The dispersed flavor probably acts as an additional barrier for conformational changes and orientation of rigid polysaccharide chains in flow field. This is in accordance with data reported in the study of SosaHerrera, Lozano-Esquivel, Ponce de León-Ramírez, and MartínezPadilla (2012) where it was shown that dispersed oil particles also induced increase in viscosity of Na-alginate aqueous mixtures. As regarding the thixotropic properties, the upward and downward

Table 2

The properties of the liquid systems: conductivity, emulsions stability, the average droplet size and power-law model fitting parameters.

\begin{tabular}{|c|c|c|c|c|c|c|c|}
\hline \multirow[t]{2}{*}{ Sample } & \multirow{2}{*}{$\begin{array}{l}\text { Conductivity } \\
(\mathrm{mS} / \mathrm{cm})\end{array}$} & \multirow[t]{2}{*}{ Emulsion stability (\%) } & \multirow{2}{*}{$\begin{array}{l}\text { Average droplet } \\
\text { size }(\mu \mathrm{m})\end{array}$} & \multirow{2}{*}{$\begin{array}{l}\text { Homogenous subsets of average } \\
\text { flavor droplet size }\end{array}$} & \multicolumn{3}{|c|}{ Parameters of the power-law model } \\
\hline & & & & & $\mathrm{k}\left(\mathrm{Pa} \mathrm{s}^{\mathrm{n}}\right)$ & $n$ & $R^{2}$ \\
\hline$S_{0.02}^{0}$ & $3.94 \pm 0.01$ & - & - & - & $1.98 \pm 0.29$ & $0.63 \pm 0.02$ & 0.995 \\
\hline$S_{0.03}^{0}$ & $5.72 \pm 0.07$ & - & - & - & $9.00 \pm 1.36$ & $0.54 \pm 0.02$ & 0.993 \\
\hline$S_{0.02}^{5}$ & $3.67 \pm 0.11$ & $98.7 \pm 1.2$ & $4.9 \pm 2.2$ & 1 & $2.32 \pm 0.32$ & $0.62 \pm 0.02$ & 0.995 \\
\hline$S_{0.03}^{5}$ & $5.44 \pm 0.30$ & $98.0 \pm 1.6$ & $6.9 \pm 6.3$ & 1,2 & $9.72 \pm 1.34$ & $0.53 \pm 0.02$ & 0.992 \\
\hline$S_{0.02}^{103}$ & $3.36 \pm 0.21$ & $97.4 \pm 1.9$ & $7.5 \pm 5.0$ & 2 & $2.76 \pm 0.42$ & $0.60 \pm 0.02$ & 0.993 \\
\hline $\begin{array}{l}0.02 \\
S_{0.03}^{10}\end{array}$ & $4.95 \pm 0.43$ & $97.5 \pm 2.3$ & $11.7 \pm 11.0$ & 3 & $11.80 \pm 1.17$ & $0.50 \pm 0.01$ & 0.987 \\
\hline
\end{tabular}

\footnotetext{
${ }^{a}$ Homogeneous subsets of flavor droplet means for different solutions, obtained from Tukey's test.
} 


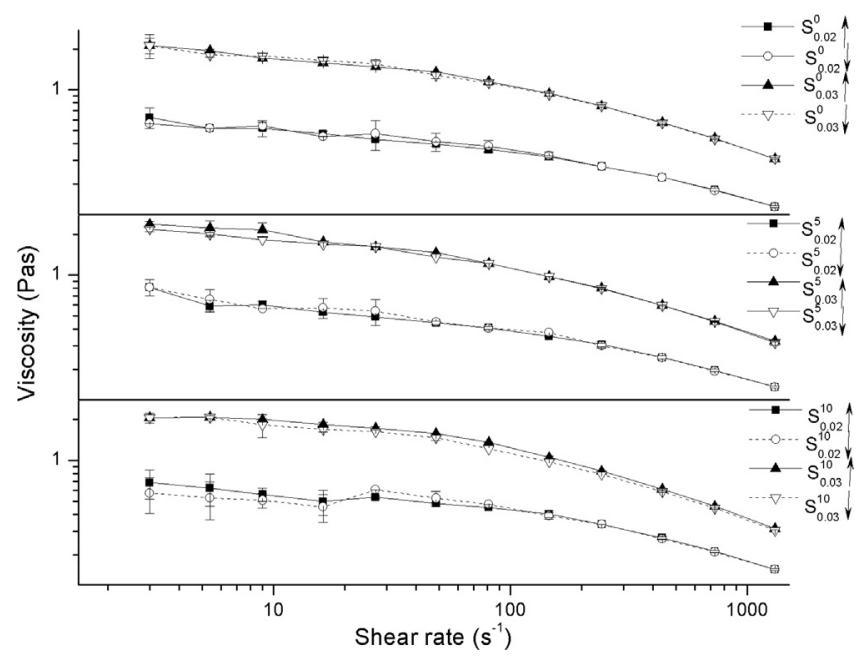

Fig. 2. Viscosity as function of shear rate for the liquid systems. Closed and open symbols represent up-curve and down-curve, respectively (as also indicated by uparrow and down-arrow, respectively).

flow curves superpose for all the samples with the exception of $S_{0.03}^{10}$, for which a small hysteresis loop was observed (see Fig. 2). According to Ma et al. (2014) and Tabeei, Samimi, Khorram, and Moghadam (2012) sodium alginate aqueous solutions in general exhibit a certain thixotropic property, and the greater the sodium alginate concentrations, the stronger the thixotropic properties. However, this was not observed by some authors, e.g. Oliveira et al. (2010) who claimed that alginate solutions even at high concentrations (up to $10 \mathrm{w} / \mathrm{v} \%$ ) did not present thixotropy. The hysteresis loop area for $S_{0.03}^{10}$ was calculated according to Equation (2), with the consistency coefficient $k$ and flow index $n$ presented in Table 2 and consistency coefficient $k^{\prime}$ of $10.40 \pm 1.01 \mathrm{~Pa} \mathrm{~s}^{-0.51}$, and flow index $n^{\prime}$ of $0.51 \pm 0.01$ (both obtained by fitting the downward flow curve with Power law model (Equation (1)). Thus obtained value was $12,850 \mathrm{~Pa} \mathrm{~s}^{-1}$.

Conductivities of all liquid samples were measured, in order to examine the effects of particles' forming under electrostatic field. From the literature it is known that, by increasing conductivity of the polymer solution (for example by adding a small amount of an organic salt) it is possible to dramatically decrease the size of particles produced by electrohydrodynamic atomization (Xie, Lim, Phua, Hua, \& Wang, 2006), the process based on the same principles as the one used here. However, the influence of conductivity has not been explored yet on the particular set-up of electrostatic extrusion. The results of conductivity measurements done here are presented in Table 2. Sodium alginate is a polyelectrolyte having high conductivity and the values obtained for pure Na-alginate (samples $S_{0.02}^{0}$ and $S_{0.03}^{0}$ ) are very close to literature data (Li et al., 2013). As expected, lower concentrated Na-alginate solutions appeared to be less able to conduct electricity. The results presented in this study indicate that $\mathrm{D}$-limonene induce damping effects and decrease in conductivity in the liquid systems (Table 2). The conductivity of solutions of sodium alginate is reduced by 14\% after adding the flavor, indicating that the flavor reduced the repulsive forces among the polyanionic sodium alginate molecules.

The stability of all prepared emulsions was estimated $1 \mathrm{~h}$ after they were left standing, as within this time interval it was possible to complete the immobilization process, including the formation of solid beads. In line with literature reports, emulsion stability is an important property from the viewpoint of the encapsulation efficiency as well as the product quality (Chan, 2011). It could be expected that concentration higher than $10 \% \mathrm{w} / \mathrm{w}$ of the flavor would cause destabilization of the emulsion. However, our observation (screening for phase separation), as well as the analysis (Table 2) showed that emulsions with both concentrations of D-limonene $(5 \%$ $\mathrm{w} / \mathrm{w}$ and $10 \% \mathrm{w} / \mathrm{w}$ ) were stable for a period of $1 \mathrm{~h}$. For the sake of comparison, Chan (2011) has shown that emulsions of palm oil in alginate were stable for $1 \mathrm{~h}$ if the alginate concentration was higher than $25 \mathrm{~g} / \mathrm{L}$. Furthermore, our measurements confirmed that stability did not depend appreciably on the amount of the dispersed phase (Table 2).

The influence of concentrations of both components on the size of D-limonene droplets (obtained by light microscopy) is presented in Fig. 3. The size of droplets was measured in four different solutions: $5 \% \mathrm{w} / \mathrm{w}$ flavor in $0.02 \mathrm{~g} / \mathrm{mL} \mathrm{Na}$-alginate $\left(S_{0.02}^{5}\right), 10 \% \mathrm{w} / \mathrm{w}$ flavor in $0.02 \mathrm{~g} / \mathrm{mL} \mathrm{Na}$-alginate $\left(S_{0.02}^{10}\right), 5 \% \mathrm{w} / \mathrm{w}$ flavor in $0.03 \mathrm{~g} / \mathrm{mL} \mathrm{Na}$ alginate $\left(S_{0.03}^{5}\right)$, and $10 \% \mathrm{w} / \mathrm{w}$ flavor in $0.03 \mathrm{~g} / \mathrm{mL}$ Na-alginate $\left(S_{0.03}^{10}\right)$. The size of D-limonene droplets within the solutions ranged from $1.0 \mu \mathrm{m}$ to $14.5 \mu \mathrm{m}$ for $S_{0.02}^{5}$, from $1.5 \mu \mathrm{m}$ to $24.9 \mu \mathrm{m}$ for $S_{0.02}^{10}$, from $1.6 \mu \mathrm{m}$ to $38.5 \mu \mathrm{m}$ for $S_{0.03}^{5}$ and from $1.9 \mu \mathrm{m}$ to $52.1 \mu \mathrm{m}$ for $S_{0.03}^{10}$. The mean values for droplets size ranged from $4.9 \mu \mathrm{m}$ for $S_{0.02}^{5}$ to $11.7 \mu \mathrm{m}$ for $S_{0.03}^{10}$. The data were further analyzed with oneway ANOVA, which showed that the mean differences between droplets size in four different solutions were statistically significant $(F(3,384)=16.680, p<0.001)$. The means are further analyzed with Tukey's HSD test, to find those that differ. Post hoc comparisons using the Tukey HSD test indicated that the mean score for the droplets sizes in $S_{0.03}^{10}$ was significantly different than the mean of the droplets sizes in other three samples. The droplets size in $S_{0.03}^{5}$, however, was significantly different than the droplets size in $S_{0.03}^{10}$ only.

The results indicate that higher concentration of alginate influenced the appearance of D-limonene droplets with higher mean droplet sizes. This is expected, as hydrophilic polysaccharide hydrocolloid, such is alginate, should have a low surface activity. However, the opposite outcome is reported by Chan (2011) who demonstrated that smaller oil droplets are developed if alginate is

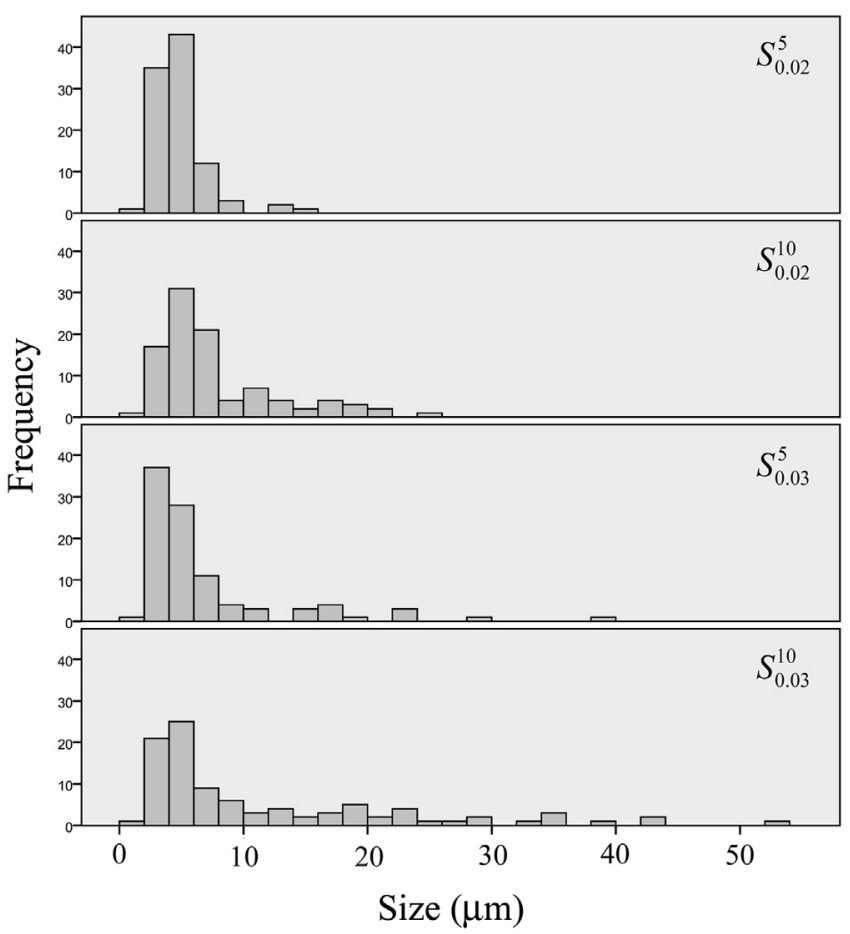

Fig. 3. Size distribution of D-limonene droplets in four different liquid systems of Naalginate-D-limonene: $S_{0.02}^{5}, S_{0.02}^{10}, S_{0.03}^{5}$ and $S_{0.03}^{10}$. 
more concentrated. It seems that an increase in viscosity of the continuous phase elevates resistance for effective dispersion of flavor droplets. In order to get smaller flavor droplets and consequently, to create more stable emulsions, higher power inputs are needed and can be achieved, for example, by ultra high-pressure homogenization (Kaushik \& Roos, 2007).

\subsection{Effects of the liquid systems structural organization and applied voltage on the beads properties}

The average size of the wet and dried beads is shown in boxplots (Fig. 4).

Without applying electrostatic field, wet beads with diameters in the range from $\sim 2100$ to $\sim 2350 \mu$ m were produced. Under the applied voltage of $6.5 \mathrm{kV}$ (other processing parameters were the same) smaller beads were formed with diameters in the range from $\sim 960$ to $\sim 1450 \mu \mathrm{m}$. The mean differences between systems were tested with ANOVA, which showed that groups of data corresponding to different systems were significantly different $(F(11,839)=75.739, p<0.001)$. Tukey's post-hoc test showed significant difference between dimaters of beads produced with and without electrostatic force.

From the results presented so far it follows that the increase in alginate concentration leads to statistically significant increase in hydrogel beads diameter in case of those produced by electrostatic extrusion $(F(1,482)=8.009, p=0.005$ for wet particles, $F(1,367)=6.129, p=0.014$ for dried particles). These findings can be comprehended as a consequence of increased viscosity of more concentrated Na-alginate solutions/emulsions, determined here and also elsewhere (Manojlović et al., 2006); while obviously, conductivity did not correlate with the size of beads. Also, it seems that the increase in viscosity deteriorated the beads uniformity. The observed increase in standard deviations is in agreement with mechanisms of droplet formation under action of the electrostatic field (Bugarski et al., 2006). Namely, a detachment of the main drop of the high-viscous solution at the tip of the needle is accompanied by detachment of the linking filament, which then brakes up into a large number of smaller droplets resulting in non-uniform size distribution. Since the size of dry particles has a direct relationship with the size of wet beads, the results for the size of dry beads seem to be qualitatively consistent with the correlation laws established for hydrogel forms. Fig. 5A and B shows microphotographs of the wet and dried beads produced by simple dripping technique (without applying electrostatic force) and electrostatic extrusion (by applying electrostatic force), respectively.

Since systems differ in amount of D-limonene, the influence of this factor was also observed and tested. ANOVA test showed that there is a statistically significant difference between diameters of beads with different content of $\mathrm{D}$-limonene, both among wet beads $(F(2,480)=3.912, p=0.021)$ and dried beads $(F(2,356)=51.033$, $p<0.001)$. Eta-squared $\left(\eta^{2}\right)$ measure of the flavor concentration effect on beads size was 0.02 for wet beads, which is usually taken as small, and 0.22 for dried beads, which is taken as a large effect.

Sphericity factor (SF) was used to quantitatively express the roundness of the beads: the zero value designates a perfect sphere, while as higher the SF value is, more pronounced distortion of shape occurs. Sphericity factor for wet and dried beads formed under electrostatic field and for those formed by simple dropping under gravity (without electrostatic field) are shown in Table 3. The results show that elongated forms of hydrogel beads were produced when processing flavor in $0.03 \mathrm{~g} / \mathrm{mL}$ alginate based emulsions and only if electrostatic potential was applied. It has been reported that extrusion of high viscosity polymer solutions (i.e. high concentration polymer solutions) gives deformed particles having shape of eggs or drops (Levic et al., 2013; Prüsse et al., 2008). This is again the direct outcome of the polymer flow behavior in the electrostatic field: as a result of applied voltage, the spherical shape of the liquid meniscus at the tip of the needle is deformed into a conical shape. Consequently, the alginate solution flows through this weak area at an increasing rate, causing formation of a neck and the neck formation is more pronounced as the alginate solution is more viscous (i.e. more concentrated). After its detachment and disintegration, the falling linking filaments will solidify into elongated beads (Poncelet, Babak, Neufeld, Goosen, \& Bugarski, 1999). After drying process, the sphericity of the beads was changed toward irregular shapes, which is noticed by values for Sphericity factor (SF) higher than 0.05 , and the worst values are those found for empty beads. The last assertion, together with the results for the effect of D-limonene on size of dried beads, leads to a conclusion that the flavor stabilizes beads morphology during drying proces.

Additionally, the influence of drying process and the addition of flavor on morphology of beads was evaluated by SEM (Fig. 6).

The images presented in Fig. 6 reveal that the problem of the gel cracking upon drying which is noticed in case of empty beads (Fig. 6a) is overcomed by addition of flavor (Fig. 6c), which, obviously, acted as a filler. As it can be seen, surface roughness of the
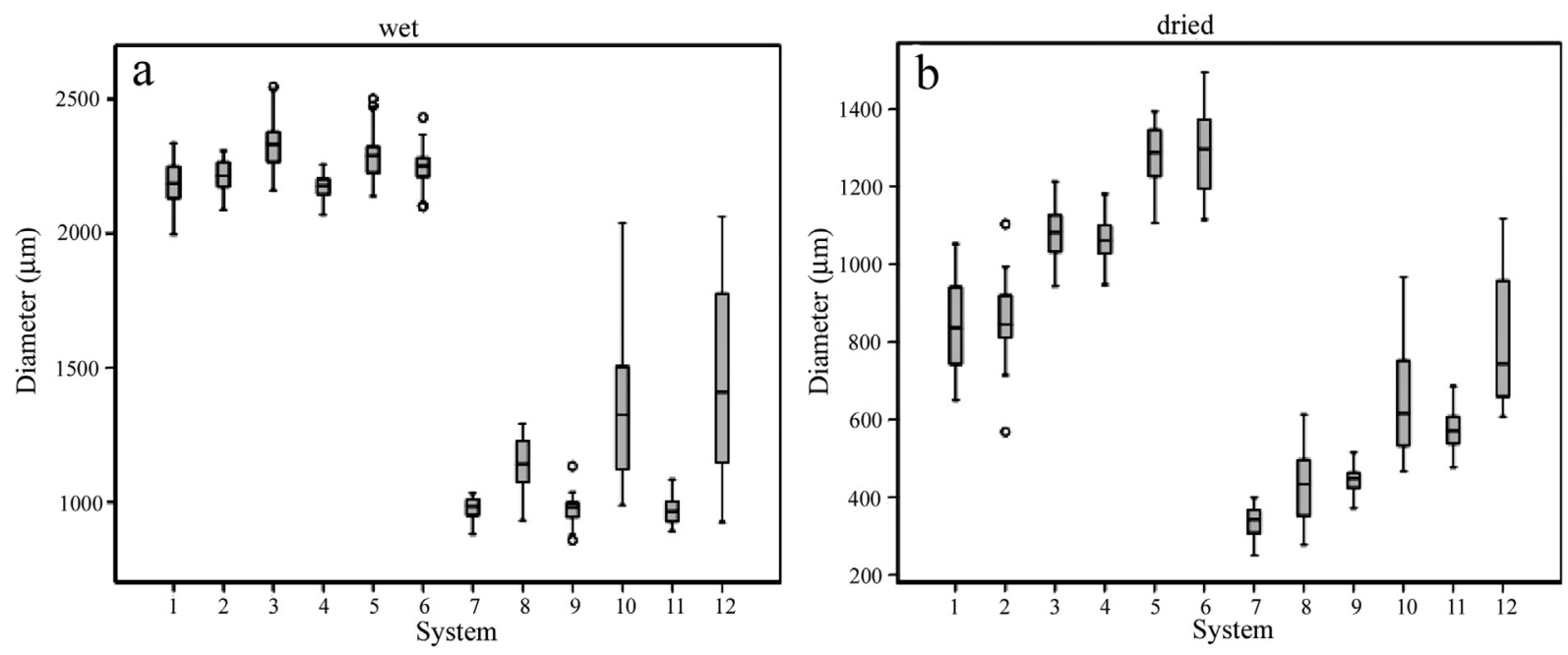

Fig. 4. Box-plots of wet (a) and dried (b) beads diameters. The systems formulations and preparation conditions are listed in Table 1 (see above). 


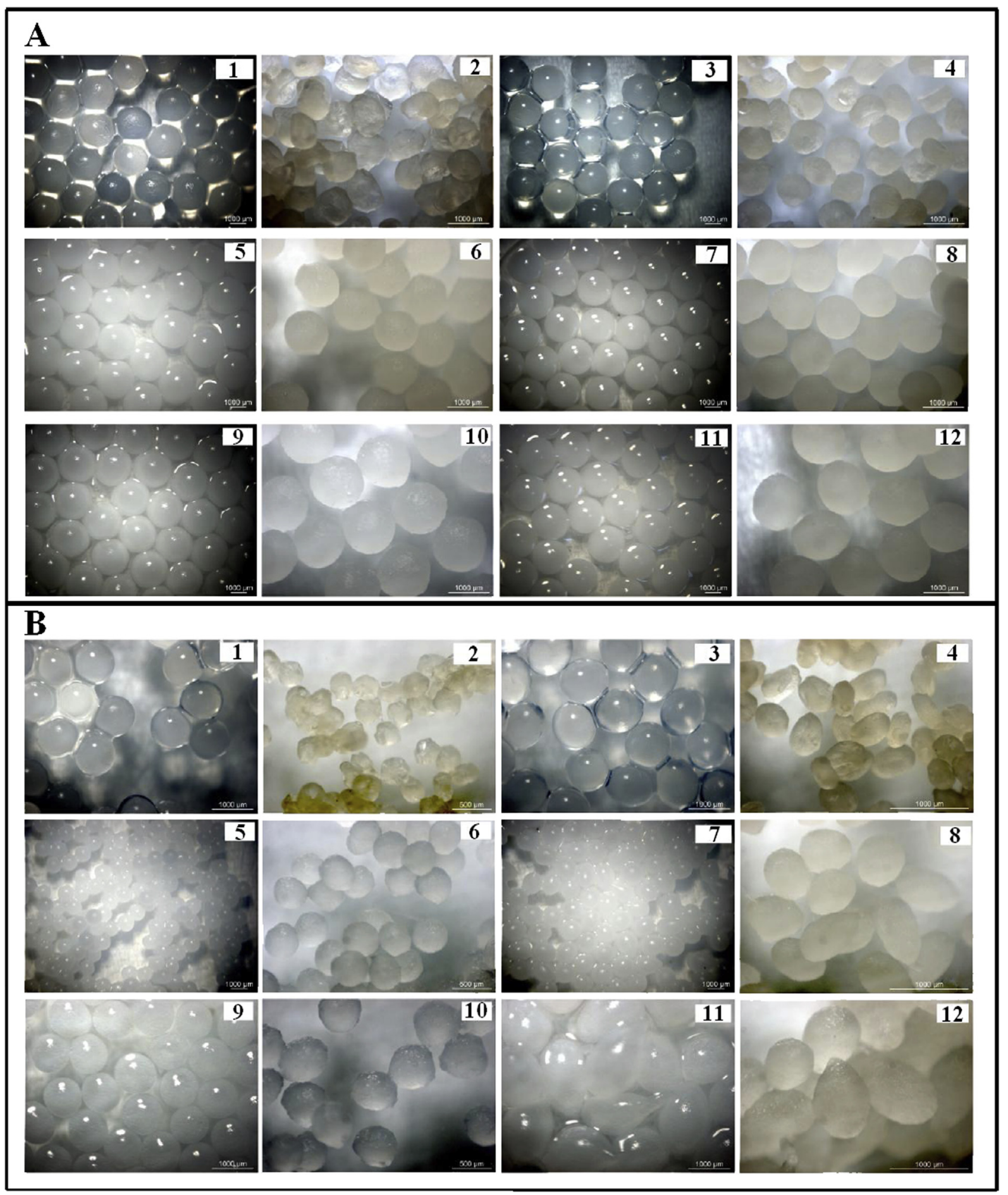

Fig. 5. A. Beads produced without applying electrostatic force: $S_{0.02}^{0}\left(1\right.$-wet, 2 -dry); $S_{0.03}^{0}$ (3-wet, 4 -dry), $S_{0.02}^{5}\left(5\right.$-wet, 6-dry), $S_{0.03}^{5}\left(7\right.$-wet, 8-dry), $S_{0.02}^{10}\left(9\right.$-wet, 10 -dry), $S_{0.03}^{10}(11$-wet, 12 dry). B. Beads produced by applying electrostatic force $(6.5 \mathrm{kV})$. Sample design is the same as in the case of samples presented in Fig. $5 \mathrm{~A}$.

$0.02 \mathrm{~g} / \mathrm{mL}$ Ca-alginate beads containing $5 \% \mathrm{w} / \mathrm{w}$ of the flavor (Fig. 6d) was more pronounced compared to the $0.02 \mathrm{~g} / \mathrm{mL} \mathrm{Ca-}$ alginate beads without flavor (Fig. 6b).

The shrinkage of beads upon drying is quantified via Shrinkage factor, the values are presented in Table 3. It seems that the shrinkage factor correlates with the amount the flavor compound so that the beads shrunk less if they had higher content of the flavor, as there was a less of water to evaporate. According to the results presented in Table 3, D-limonene was immobilized within Ca-alginate matrix with efficiency of 50 to $\sim 77 \%$. The values are lower in comparison with the literature data on encapsulation of oily compounds in beads of calcium alginate by extrusion-dripping technique (Chan, 2011; Chang \& Dobashi, 2003; Peniche, Howland, Corrillo, Zaldívar, \& Argüelles-Monal, 2004), but in a good agreement with reports on encapsulation of some plant aqueous extract (Stojanovic et al., 2012). One of the reasons is that alginate used in 
Table 3

The morphological characteristics and immobilization efficiency of beads produced with and without applying electrostatic force.

\begin{tabular}{|c|c|c|c|c|c|c|c|c|}
\hline \multirow[t]{2}{*}{ Form- ulation no. } & \multirow[t]{2}{*}{ Sample } & \multicolumn{2}{|c|}{ Beads size $(\mu \mathrm{m})$} & \multicolumn{2}{|c|}{ Sphericity factor } & \multirow{2}{*}{$\begin{array}{l}\text { Shrinkage } \\
\text { factor }\left(\mathrm{k}_{\mathrm{SF} \text { (drying) }}\right)^{\mathrm{c}}\end{array}$} & \multirow{2}{*}{$\begin{array}{l}\text { Immobilization } \\
\text { efficiency (\%) }\end{array}$} & \multirow{2}{*}{$\begin{array}{l}\text { Homogenous } \\
\text { subsets } \\
\text { (Tukey test) }^{\mathrm{d}}\end{array}$} \\
\hline & & Wet beads & $\overline{\text { Dried beads }}$ & Wet beads ${ }^{\mathrm{a}}$ & Dried beads $^{b}$ & & & \\
\hline 1 & $S_{0.02}^{0}$ & $2184 \pm 81$ & $846 \pm 123$ & 0.008 & 0.10 & 0.61 & - & 4 \\
\hline 2 & $S_{0.03}^{0.02}$ & $2215 \pm 63$ & $851 \pm 97$ & 0.004 & 0.054 & 0.61 & - & 4 \\
\hline 3 & $S_{0.02}^{5}$ & $2331 \pm 92$ & $1078 \pm 65$ & 0.023 & 0.051 & 0.54 & $54.5 \pm 10.7$ & 4,5 \\
\hline 4 & $S_{0.03}^{5}$ & $2173 \pm 46$ & $1067 \pm 56$ & 0.01 & 0.032 & 0.51 & $63.4 \pm 4.4$ & 4,5 \\
\hline 5 & $S_{0.02}^{10}$ & $2288 \pm 84$ & $1287 \pm 79$ & 0.012 & 0.019 & 0.44 & $70.3 \pm 0.7$ & 5 \\
\hline 6 & $S_{0.03}^{10}$ & $2247 \pm 64$ & $1285 \pm 99$ & 0.006 & 0.067 & 0.43 & $68.3 \pm 5.6$ & 5 \\
\hline 7 & $S_{0.02}^{0.03}$ & $975 \pm 43$ & $331 \pm 42$ & 0.01 & 0.07 & 0.66 & - & 1 \\
\hline 8 & $S_{0.03}^{0.02}$ & $1143 \pm 91$ & $432 \pm 98$ & 0.003 & 0.188 & 0.62 & - & $1,2,3$ \\
\hline 9 & $S_{0.02}^{5}$ & $968 \pm 51$ & $442 \pm 38$ & 0.016 & 0.048 & 0.54 & $60.6 \pm 5.5$ & 1 \\
\hline 10 & $S_{0.03}^{5}$ & $1334 \pm 248$ & $649 \pm 139$ & 0.16 & 0.165 & 0.51 & $52.7 \pm 3.0$ & 2,3 \\
\hline 11 & $S_{0.02}^{10}$ & $968 \pm 47$ & $571 \pm 50$ & 0.016 & 0.055 & 0.41 & $77.3 \pm 3.7$ & 1,2 \\
\hline 12 & $S_{0.03}^{10}$ & $1452 \pm 352$ & $811 \pm 165$ & 0.21 & 0.183 & 0.44 & $67.1 \pm 4.8$ & 3 \\
\hline
\end{tabular}

a The average absolute deviation less than $11 \%$.

b The average absolute deviation less than $23 \%$.

c The average absolute deviation less than $23 \%$.

d Homogeneous subsets of beads means for different solutions, obtained from Tukey's test.

this study is poor in guluronic acid $(G)$ residues $(M / G=1.56)$, having lower gelling density at the emulsion droplet surface, thus yielding a lower encapsulation efficiency in comparison to high G alginates. The immobilization efficiency found for both alginate concentrations showed the same trend, increasing with the increase in the flavor loading.

\subsection{The rehydration study}

The rehydration of the dried beads was performed in (1) water and (2) phosphate buffer (PBS). The results of rehydration tests indicate that swelling of beads depended on the flavor contents, bead size and alginate concentration. Generally, swelling depends on sub processes such as: (1) transport of water and $\mathrm{Na}^{+}$ions to gel bead by diffusion mechanism and (2) gel disintegration caused by partial $\mathrm{Na}^{+}-\mathrm{Ca}^{2+}$ ion exchange in case of PBS induced hydration.
Actually, when calcium alginate beads are brought in contact with aqueous medium of higher $\mathrm{pH}$, ion exchange takes place between the gel-forming $\mathrm{Ca}^{2+}$ ions and $\mathrm{Na}^{+}$ions of the dissolution medium. As the $\mathrm{Ca}^{2+}$ ions are exchanged, electrostatic repulsion between the ionized carboxylate anions of alginic acid accelerates the swelling and erosion of alginate gel (Kikuchi, Kawabuchi, Sugihara, Sakurai, \& Okano, 1997). Moreover, upon ionization, the counter-ion concentration inside the polymeric network increases, and an osmotic pressure difference exists between the internal and external solutions of the beads (Soppimath, Kulkarni, \& Aminabhavi, 2001).

In water, swelling of the dry beads is mainly attributed to the hydration of the hydrophilic groups of alginate. Based on experimental results of this study, duration of reversible swelling $\left(t_{w}\right)$ in water was $\sim 20 \mathrm{~min}$. It represented the time needed for elastic volumetric deformation of gel caused by water input. After this time swelling of Ca-alginate gel in water was equilibrated as it was
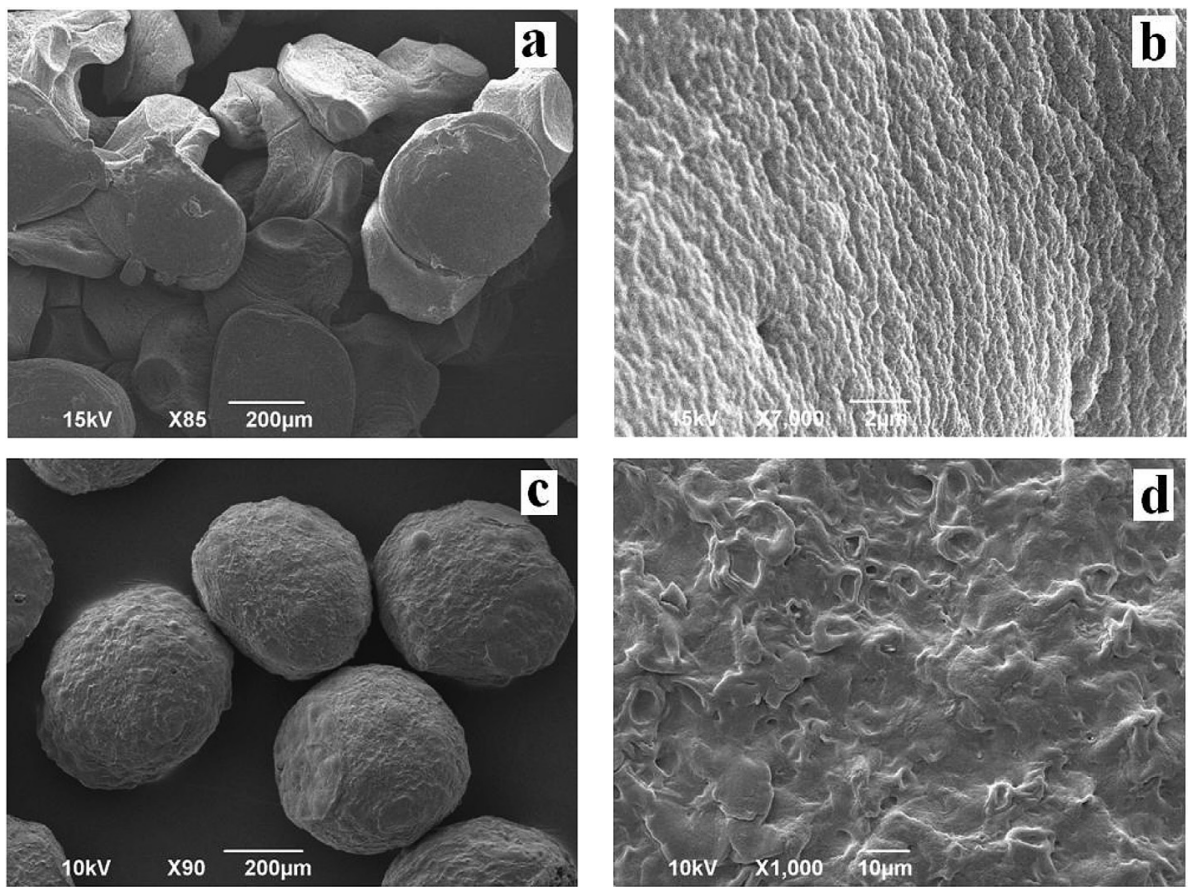

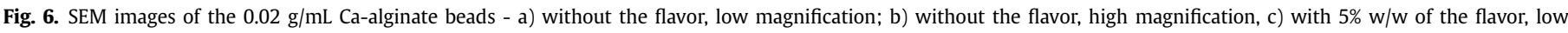
magnification, d) with $5 \% \mathrm{w} / \mathrm{w}$ of the flavor, high magnification. 
shown in Fig. 7a-b. Our results suggest that reversible swelling was more evident for the smaller (produced by applying voltage) than for the larger beads (produced by simple dripping technique) and it should be related to larger interface, in the case of the smaller beads. Reversible swelling was more intensive for $0.03 \mathrm{~g} / \mathrm{mL} \mathrm{Ca-}$ alginate compared to $0.02 \mathrm{~g} / \mathrm{mL} \mathrm{Ca}$-alginate beads. This is in accordance with the fact that higher concentration of hydrophilic alginate chains per bead induced higher water adsorption. Embedding of the flavor within the beads caused decrease of reversible swelling. It seems that immobilized flavor acted as a physical barrier for water transport through the gel on one side, and it also suggests that there is no affinity between alginate and flavor via electrostatic attraction that would otherwise hinder side-byside aggregation of alginate egg-box junctions (Vreeker, Li, Fang, Appelqvist, \& Mendes, 2008). Addition of $5 \% \mathrm{w} / \mathrm{w}$ flavor to $0.02 \mathrm{~g} / \mathrm{mL}$ Ca-alginate beads didn't have significant influence on swelling process. However, addition of $10 \% \mathrm{w} / \mathrm{w}$ flavor to $0.02 \mathrm{~g} / \mathrm{mL}$ in case of the smaller beads induced dispersion of experimental data (Fig. 7a-b). The results indicate a destabilization of $0.02 \mathrm{~g} / \mathrm{mL}$ alginate gel containing such high amount of the flavor which occurred during water input. The phenomenon was not observable for the larger beads.

Swelling of Ca-alginate gel in phosphate buffer consisted of two contributions: (1) reversible swelling caused by diffusion of solution into the gel matrix and (2) irreversible swelling caused by partial disintegration of junction zones induced by $\mathrm{Na}^{+}-\mathrm{Ca}^{2+}$ ion exchange. In the following text, the kinetic equation for estimating the irreversible swelling of empty Ca-alginate gel beads will be developed, followed by model modifications for describing the influence of the flavor on irreversible swelling.

The stability of Ca-alginate can be explained by disintegration of junction zones of the gel (Pajić-Lijaković, Plavšić, Bugarski, \& Nedović, 2007). Partial $\mathrm{Na}^{+}-\mathrm{Ca}^{2+}$ ions exchange and corresponding disintegration of the junction zones occurred in the time interval $t \in\left(0, t_{\infty}\right)$ (where $t_{\infty} \approx 240$ min was the time up to which the beads kept their structural integrity). Density of disintegrated
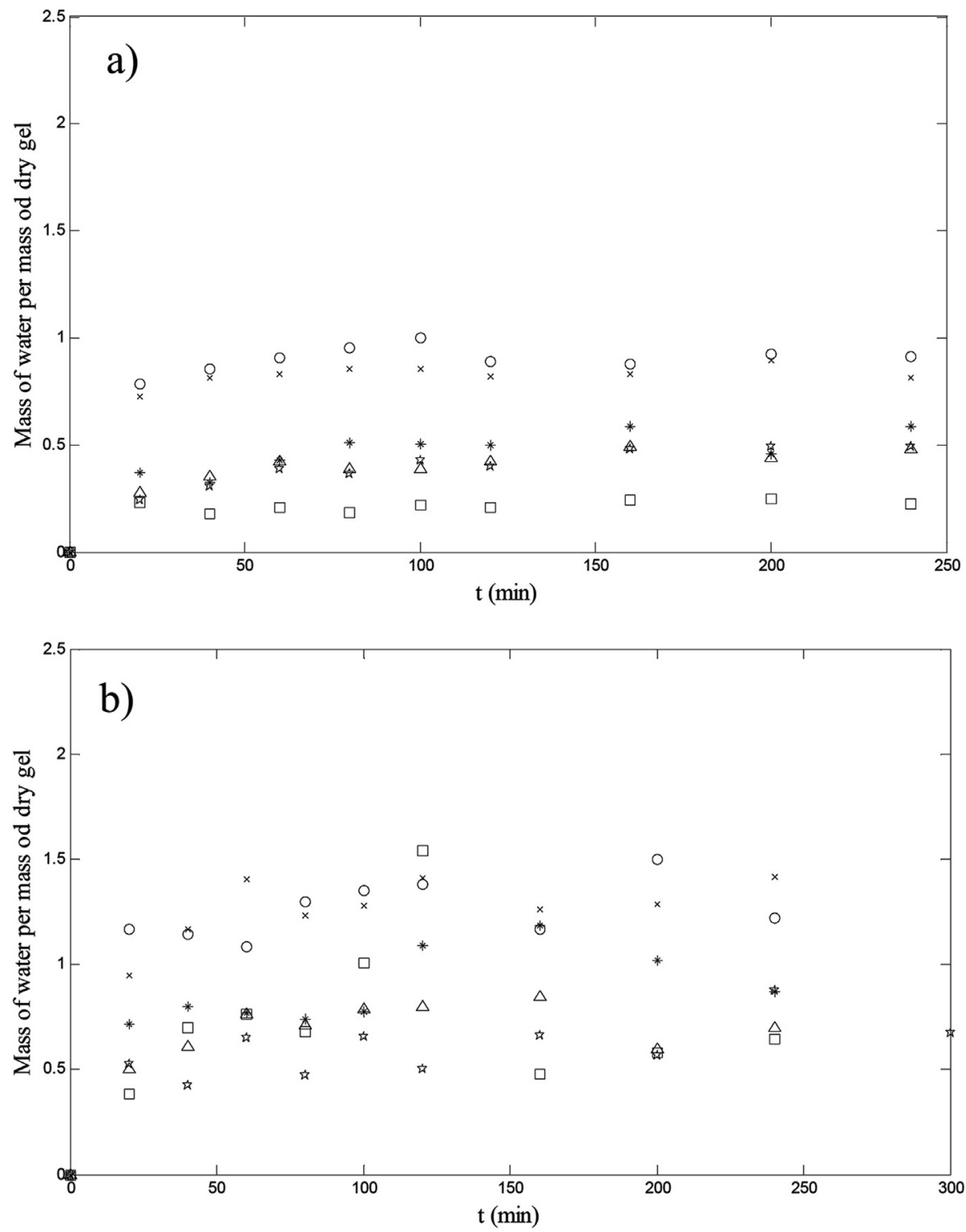

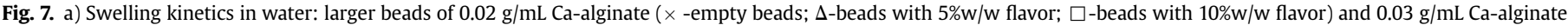

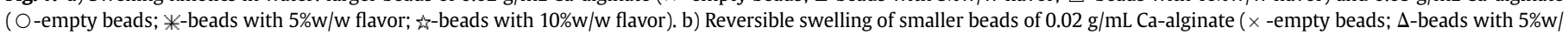
w flavor; $\square$-beads with $10 \% \mathrm{w} / \mathrm{w}$ flavor) and $0.03 \mathrm{~g} / \mathrm{mL}$ Ca-alginate ( $\bigcirc$-empty beads; $*$-beads with $5 \% \mathrm{w} / \mathrm{w}$ flavor; 
junction zones within the Ca-alginate gel was expressed as: $y(t) \sim M(t)$, where $y(t)$ was the density of disintegrated junction zones and $M(t)$ was the mass of the solution per mass of dry gel which was related to irreversible swelling.

In this study, the first order kinetic model equation was used for estimating the disintegration of Ca-alginate beads without the flavor in phosphate buffer. The similar modeling equation has been already applied for describing swelling of various gel types (Ganji, Vasheghani-Farahani, \& Vasheghani-Farahani, 2010; Pasparakis \& Bouropoulos, 2006). The model equation was expressed as:

$\frac{\mathrm{d} M(t)}{\mathrm{d} t}=k\left(M_{\infty}-M(t)\right)$

where $k$ was the kinetic constant of gel disintegration and $M_{\infty}$ was the mass of the solution at equilibrium per mass of dry gel which induces irreversible swelling i.e. $M_{\infty}=M\left(t_{\infty}\right)$. The initial condition was: at $t=0$ the corresponding mass was $M(t=0)=0$. After solving the model Equation (7) was expressed as:

$M(t)=M_{\infty}\left[1-e^{-k t}\right]$

However, the model Equation (7) should be additionally modified for describing the irreversible swelling of Ca-alginate gel which contains the immobilized flavor. The modification should include the damping effects caused by the immobilized flavor on the kinetic of gel disintegration. Consequently, fractional derivatives were introduced into Equation (7) for modeling the damping effects as:

${ }_{0}^{C} D_{t}^{\beta} M(t)=k\left(M_{\infty}-M(t)\right)$

where ${ }_{0}^{C} D_{t}^{\beta}$ was Caputo's fractional derivative operator and the model parameter $\beta$ represented the damping coefficient in the range $0 \leq \beta<1$. Lower value of the damping coefficient indicated
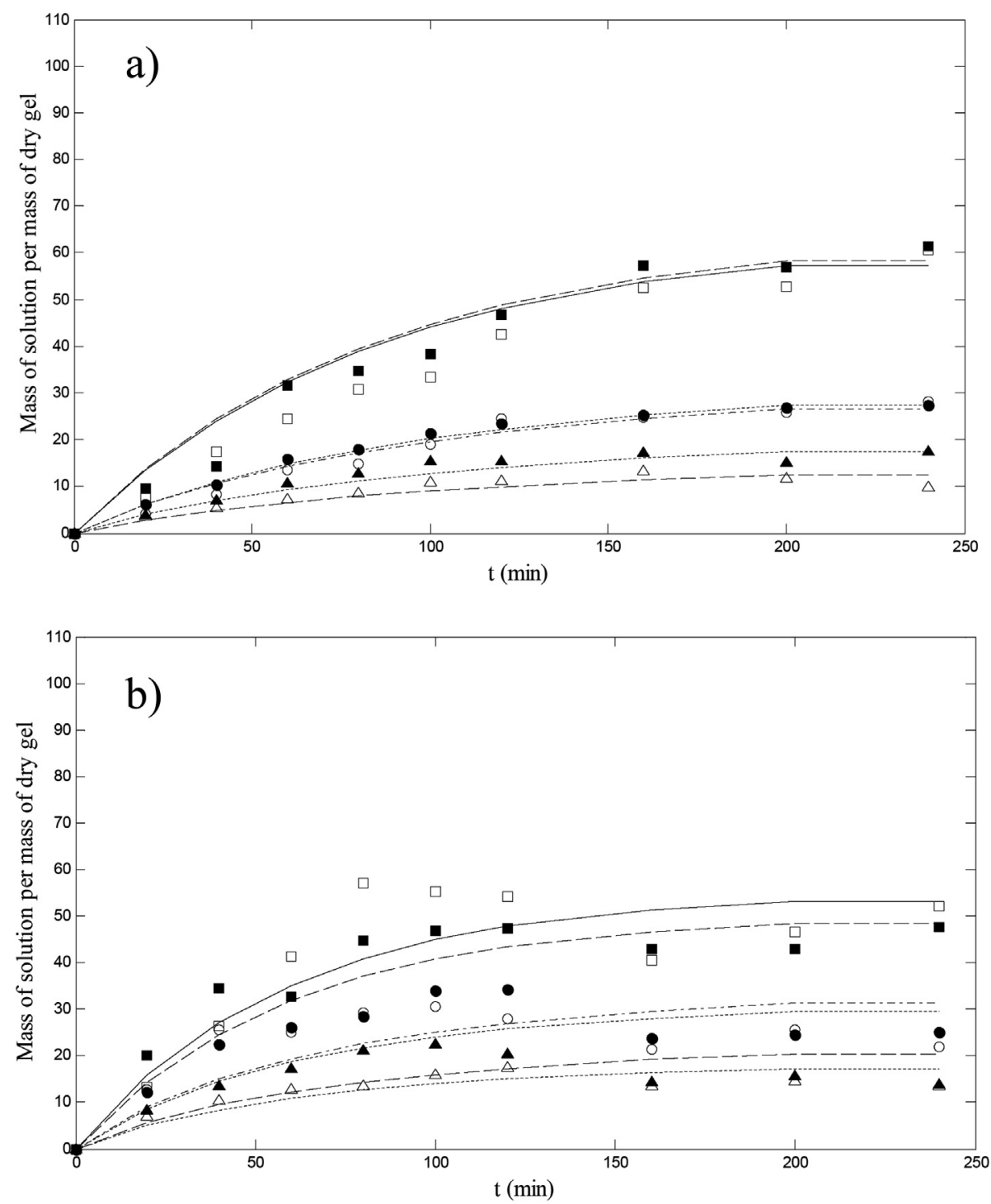

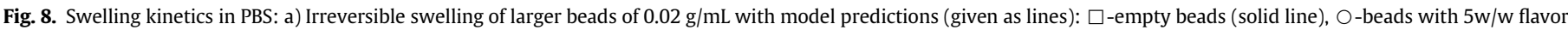

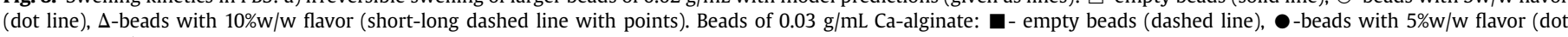

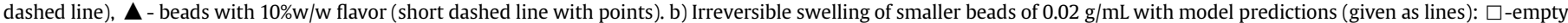

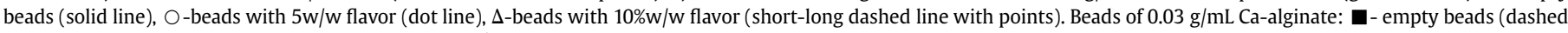
line), -beads with $5 \% \mathrm{w} / \mathrm{w}$ flavor (dot dashed line), $\boldsymbol{\Delta}$ - beads with $10 \% \mathrm{w} / \mathrm{w}$ flavor (short dashed line with points). 
higher damping effects (Podlubny, 1999). We used Caputo's definition of the fractional derivative of the function $M(t)$, given as follows (Podlubny, 1999): for $0 \leq \beta<1$ the derivative $\operatorname{is}_{0}^{C} D_{t}^{\beta}(M(t))=1 / \Gamma(\beta-1) \int_{0}^{t^{*}} M\left(t^{\prime}\right)^{(1)} /\left(t-t^{\prime}\right)^{\beta} \mathrm{d} t^{\prime}$, where $\Gamma(\beta-1)$ is gamma function. When the damping coefficient tends to one i.e. $\beta \rightarrow 1$, the fractional derivative becomes ${ }_{0}^{C} D_{t}^{\beta} \rightarrow \mathrm{d} / \mathrm{d} t$. For such condition, damping effects could be neglected and the model Equation (7) and Equation (9) became the same. After solving the model Equation (9) the following expression was derived:

$M(t)=M_{\infty}\left[1-E_{\beta, 1}\left(-k t^{\beta}\right)\right]$

where $E_{\beta, 1}\left(-k t^{\beta}\right)$ was Mittag-Leffler function (Podlubny, 1999) equal to $E_{\beta, 1}\left(-k t^{\beta}\right)=\sum_{k=0}^{\infty}\left(-k t^{\beta}\right)^{k} / \Gamma(1+\beta k)$.

The model parameters: the kinetic constant $k$ and the damping coefficient $\beta$ were determined during fitting procedure by comparing experimental data with the model predictions calculated using Equation (8) for the gel without the flavor and Equation (10) for the gel with the immobilized flavor.

The model predictions and experimental data on Ca-alginate gel swelling, with and without the immobilized flavor, are shown in Fig. $8 \mathrm{a}-\mathrm{b}$.

Similarly as in the case of swelling in water, it can be seen in Fig. 8a-b that swelling in phosphate buffer was more pronounced for the smaller Ca-alginate beads, most probably due to larger contact surface. Irreversible swelling of $0.02 \mathrm{~g} / \mathrm{mL}$ Ca-alginate gel was approximately the same as for $0.03 \mathrm{~g} / \mathrm{mL} \mathrm{Ca}$-alginate gel for the samples with and those without the flavor. These data are in accordance with the fact that both types of beads contain approximately the same concentration of junction zones, owing to the same concentration of $\mathrm{CaCl}_{2}$ used in all experiments. Irreversible swelling seems to be less pronounced as the amount of flavor increases. It seems that droplets of the flavor have a role of barrier for solute transport; thus making impossible for $\mathrm{Na}^{+}$ions to fill some parts of gel and to induce disintegration. Consequently, the presence of flavor induced damping effects of the gel disintegration process. Such complex phenomenon was estimated based on the developed mathematical model.

The values of $M(t)$, obtained from the previously explained mathematical model correlate satisfactory with the experimental data, with a relative error of $10 \%$ for the larger beads and $15 \%$ for the smaller beads. The optimal model parameters that enabled the best comparison between the experimental and calculated data are shown in Table 4.

The kinetic constant for gel disintegration $k$ was found to be dependent on the interface area. Consequently, 1.42 times higher value of $k$ is obtained for the smaller beads due to larger interface. On the other side, the damping coefficient $\beta$ is dependent on: (1) the bead size, (2) the immobilized amount of the flavor within the beads and (3) the concentration of alginate. The damping effects were pronounced for larger beads due to lower interface. On the other side, higher amount of the flavor induced more evident damping effects which were quantified by lower values of $\beta$. These results indicate that, in the case of higher amount of the immobilized flavor, bigger parts of gel porous structure were not available to disintegration process caused by $\mathrm{Na}^{+}$ions diffusion. Damping effects were slightly higher for $0.03 \mathrm{~g} / \mathrm{mL}$ Ca-alginate compared to $0.02 \mathrm{~g} / \mathrm{mL}$ Ca-alginate beads.

\subsection{Thermal stability of D-limonene within the Ca-alginate beads}

The thermal stability of immobilized D-limonene was studied by using simultaneous thermogravimetric/mass spectrometry (TG/ MS) analysis. The results of thermal analysis are shown in Fig. 9.
Table 4

The model parameters for irreversible swelling of the beads.

\begin{tabular}{llll}
\hline Formulation no. & Sample & $k\left(\mathrm{~min}^{-1}\right)$ & $\beta(-)$ \\
\hline 1 & $S_{0.02}^{0}$ & $(1.2 \pm 0.1) \times 10^{-2}$ & 1 \\
2 & $S_{0.03}^{0}$ & $(1.2 \pm 0.1) \times 10^{-2}$ & 1 \\
3 & $S_{0.02}^{5}$ & $(1.2 \pm 0.1) \times 10^{-2}$ & $0.95 \pm 0.01$ \\
4 & $S_{0.03}^{5}$ & $(1.2 \pm 0.1) \times 10^{-2}$ & $0.94 \pm 0.01$ \\
5 & $S_{0.02}^{10}$ & $(1.2 \pm 0.1) \times 10^{-2}$ & $0.92 \pm 0.01$ \\
6 & $S_{0.03}^{10}$ & $(1.2 \pm 0.1) \times 10^{-2}$ & $0.91 \pm 0.01$ \\
7 & $S_{0.02}^{0}$ & $(1.7 \pm 0.1) \times 10^{-2}$ & 1 \\
8 & $S_{0.03}^{0}$ & $(1.7 \pm 0.1) \times 10^{-2}$ & 1 \\
9 & $S_{0.02}^{5}$ & $(1.7 \pm 0.1) \times 10^{-2}$ & $0.95 \pm 0.02$ \\
10 & $S_{0.03}^{5}$ & $(1.7 \pm 0.1) \times 10^{-2}$ & $0.92 \pm 0.02$ \\
11 & $S_{0.02}^{10}$ & $(1.7 \pm 0.1) \times 10^{-2}$ & $0.93 \pm 0.02$ \\
12 & $S_{0.03}^{10}$ & $(1.7 \pm 0.1) \times 10^{-2}$ & $0.90 \pm 0.02$ \\
\hline
\end{tabular}

Simultaneous mass spectrometry analysis of released gaseous products was used to differentiate the steps in thermal release of the immobilized flavor. Two characteristic mass-to-charge ratios $(\mathrm{m} / \mathrm{z})$ were monitored: $(\mathrm{m} / \mathrm{z})=17$ for water release detection and $(m / z)=68$ for D-limonene detection. These $m / z$ values were selected from the mass spectra database as specific for targeted compounds, as explained previously. In the case of beads with flavor, water release was observed in the temperature range from $40^{\circ} \mathrm{C}$ to $180^{\circ} \mathrm{C}$, with a peak at around $75^{\circ} \mathrm{C}$ and a decreasing signal up to $180^{\circ} \mathrm{C}$. According to the literature, it is related to evaporation of different type of water from the polysaccharides (Laurienzo, Malinconico, Motta, \& Vicinanza, 2005). Our results indicated that the weight loss for empty beads was about $15 \%$. According to Lević et al. (2011), the majority of free D-limonene evaporated up to $200{ }^{\circ} \mathrm{C}$. As it can be seen from Fig. 9, the release of D-limonene occurs in temperature range from $60^{\circ} \mathrm{C}$ to $200^{\circ} \mathrm{C}$. This was verified by observation of the characteristic $m / z$ value $(m / z=68)$ of Dlimonene released during analysis. The weight loss in the applied temperature range was $\sim 35 \%$. Our results pointed that most of the immobilized D-limonene remained intact inside Ca-alginate matrix during the applied temperature regime. This is desirable effect of immobilization, especially because the applied temperature range of thermal analysis is in accordance with the temperature regime which corresponds to the conditions for thermally processed food (De Roos, 2003; 2006).

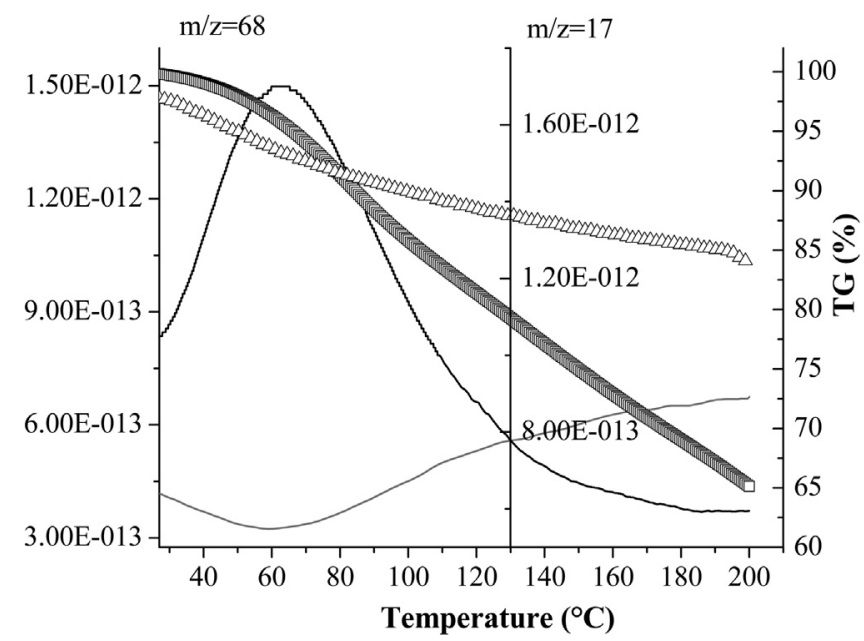

Fig. 9. TG/MS profiles obtained for immobilized D-limonene in dried Ca-alginate beads (Formulation $S_{0.02}^{10}$ )-TG $(\square)$; MS signal (ion current intensity, A) - $(m / z)=68$ (gray line), $(m / z)=17$ (black line). TG $(\Delta)$ of blank dried alginate beads (Formulation $S_{0.02}^{0}$ ). 


\section{Conclusion}

The results of this study showed that Ca-alginate beads are the suitable carriers for embedding of D-limonene in order to keep its thermal stability. It is also in accordance with the facts that the beads with up to $10 \% \mathrm{w} / \mathrm{w}$ of $\mathrm{D}$-limonene keep their structural integrity during: (1) drying process, (2) reversible swelling in water and (3) irreversible swelling in phosphate buffer. Action of $\mathrm{Na}^{+}$ions from phosphate buffer induces only partial disintegration of Caalginate network.

However, dispersed D-limonene represents the physical barrier to: (1) water evaporation during drying, (2) water diffusion during reversible swelling and (3) $\mathrm{Na}^{+}$ions diffusion during irreversible swelling. The partial disintegration of Ca-alginate network is modeled kinetically by introducing the damping effects in the form of fractional derivatives.

The size and shape of the beads depend on the rheological behavior of $\mathrm{Na}$ alginate/D-limonene emulsions and could be regulated by applying electrostatic field during the immobilization process. D-limonene influences structural ordering of alginate chains in flow field and induces increase in viscosity and reduction in conductivity of the liquid systems.

Dispersed D-limonene remains thermally stabile inside Caalginate matrix within the temperature regime up to $200{ }^{\circ} \mathrm{C}$ based on TG/MS analysis. It corresponds to the temperature regime for the bead application in food technology.

\section{Acknowledgments}

This work was supported by the Ministry of Science and Technological Development, Republic of Serbia (Project nos. III46010 and III46001) and FP7 Project AREA 316004.

\section{References}

Bugarski, B., Obradovic, B. Nedovic, V., \& Goosen, M. F. A. (2006). Electrostatic droplet generation techniquefor cell immobilization. In J. P. Shu, \& A. Spasic (Eds.), Finely dispersed systems (pp. 869-886). Boca Raton: CRC Press.

Burdock, A. B. (2004). Fenaroli's handbook of flavor ingredients (5th ed.). Boca Raton: CRC Press.

Chan, E. S., Lee, B. B., Ravindra, P., \& Poncelet, D. (2009). Prediction models for shape and size of ca-alginate macrobeads produced through extrusion-dripping method. Journal of Colloid and Interface Science, 338(1), $63-72$.

Chan, E. S. (2011). Preparation of Ca-alginate beads containing high oil content: Influence of process variables on encapsulation efficiency and bead properties. Carbohydrate Polymers, 84(4), 1267-1275.

Chan, E. S., Wong, S. L., Lee, P. P., Lee, J. S., Ti, T. B., Zhang, Z., et al. (2011). Effects of starch filler on the physical properties of lyophilized calcium-alginate beads and the viability of encapsulated cells. Carbohydrate Polymers, 83(1), 225-232.

Chang, C. P., \& Dobashi, T. (2003). Preparation of alginate complex capsules containing eucalyptus essential oil and its controlled release. Colloids and Surfaces B: Biointerfaces, 32(3), 257-262.

De Roos, K. B. (2003). Effect of texture and microstructure on flavour retention and release. International Dairy Journal, 13(8), 593-605.

De Roos, K. B. (2006). Understanding and controlling the behaviour of aroma compounds in thermally processed foods. Trends in Food Science \& Technology, 17(5), 236-243.

Del Toro-Arreola, S., Flores-Torales, E., Torres-Lozano, C., Del Toro-Arreola, A., Tostado-Pelayo, K., Ramirez-Dueñas, M. G., et al. (2005). Effect of d-limonene on immune response in BALB/c mice with lymphoma. International Immunopharmacology, 5(5), 829-838.

Ganji, F., Vasheghani-Farahani, S., \& Vasheghani-Farahani, E. (2010). Theoretical description of hydrogel swelling. A Review. Iranian Polymer Journal, 19(5), 375-398.

Kaushik, V., \& Roos, Y. H. (2007). Limonene encapsulation in freeze-drying of gum Arabic-sucrose-gelatin systems. LWT-Food Science and Technology, 40(8), 1381-1391.

Kikuchi, A., Kawabuchi, M., Sugihara, M., Sakurai, Y., \& Okano, T. (1997). Pulsed dextran release from calcium-alginate gel beads. Journal of Controlled Release, $47,21-29$.

Laurienzo, P., Malinconico, M., Motta, A., \& Vicinanza, A. (2005). Synthesis and characterization of a novel alginate-poly(ethylene glycol) graft polymer. Carbohydrate Polymers, 62(3), 274-282.
Lee, Y. K., Bouhadir, H. K., \& Mooney, J. D. (2002). Evaluation of chain stiffness of partially oxidized polyguluronate. Biomacromolecules, 3(6), 1129-1134.

Levic, S., Djordjevic, V., Rajic, N., Milivojevic, M., Bugarski, B., \& Nedovic, V. (2013). Entrapment of ethyl vanillin in calcium alginate and calcium alginate/poly(vinyl alcohol) beads. Chemical Papers, 67(2), 221-228.

Lević, S., Rac, V., Manojlović, V., Rakić, V., Bugarski, B., Flock, T., et al. (2011). Limonene encapsulation in alginate/poly (vinyl alcohol). Procedia Food Science, 1, 1816-1820.

Li, W., Li, X., Chen, Y., Li, X., Deng, H., Wang, T., et al. (2013). Poly(vinyl alcohol)/ sodium alginate/layered silicate based nanofibrous mats for bacterial inhibition. Carbohydrate Polymers, 92, 2232-2238.

Ma, J., Lin, Y., Chen, X., Zhao, B., \& Zhang, J. (2014). Flow behavior, thixotropy and dynamical viscoelasticity of sodium alginate aqueous solutions. Food Hydrocolloids, 38, 119-128.

Manojlović, V., Đonlagić, J., Obradović, B., Nedović, V., \& Bugarski, B. (2006). Investigations of cell immobilization in alginate: rheological and electrostatic extrusion studies. Journal of Chemical Technology and Biotechnology, 81, 505-510.

Nakaizumi, A., Baba, M., Uehara, H., Iishi, H., \& Tatsuta, M. (1997). d-Limonene inhibits N-nitrosobis(2-oxopropyl)amine induced hamster pancreatic carcinogenesis. Cancer Letters, 117(1), 99-103.

Nan, F., Wu, J., Qi, F., Liu, Y., Ngai, T., \& Ma, G. (2014). Uniform chitosan-coated alginate particles as emulsifiers for preparation of stable Pickering emulsions with stimulus dependence. Colloids and Surfaces A: Physicochemical and Engineering Aspects, 456, 246-252.

Nedović, V. A., Obradović, B., Leskošek-Čukalović, I., Trifunović, O., Pešić, R., \& Bugarski, B. (2001). Electrostatic generation of alginate microbeads loaded with brewing yeast. Process Biochemistry, 37(1), 17-22.

Oliveira, S. M., Almeida, I. F., Costa, P. C., Barrias, C. C., Ferreira, M. R. P., Bahia, M. F., et al. (2010). Characterization of polymeric solutions as injectable vehicles for hydroxyapatite microspheres. AAPS PharmSciTech, 11(2), 852-858.

Pajić-Lijaković, I., Plavšić, M., Bugarski, B., \& Nedović, V. (2007). Ca-alginate hydrogel mechanical transformations-The influence on yeast cell growth dynamics. Journal of Biotechnology, 129(3), 446-452.

Pasparakis, G., \& Bouropoulos, N. (2006). Swelling studies and in vitro release of verapamil from calcium alginate and calcium alginate-chitosan beads. International Journal of Pharmaceutics, 323(1-2), 34-42.

Peniche, C., Howland, I., Corrillo, O., Zaldivvar, C., \& Argüelles-Monal, W. (2004) Formation and stability of shark liver oil loaded chitosan/calcium alginate capsules. Food Hydrocolloids, 18(5), 865-871.

Podlubny, I. (1999). Fractional differential equations. In Mathematics in science and engineering (Vol 198). San Diego: Academic Press Inc.

Poncelet, D., Babak, V., Neufeld, R. J., Goosen, M., \& Bugarski, B. (1999). Theory of electrostatic dispersion of polymer solution in the production of microgel beds containing biocatalyst. Advances in Colloid Interface Science, 79, 213-228.

Prüsse, U., Bilancetti, L., Bučko, M., Bugarski, B., Bukowski, J., Gemeiner, P. et al. (2008). Comparison of different technologies for alginate beads production. Chemical Papers, 62(4), 364-374.

Rayment, P., Wright, P., Hoad, C., Ciampi, E., Haydock, D., Gowland, P., et al. (2009). Investigation of alginate beads for gastro-intestinal functionality, Part 1: in vitro characterization. Food Hydrocolloids, 23, 816-822.

Sahraoui, N., Abert Vian, M., El Maataoui, M., Boutekedjiret, C., \& Chemat, F. (2011). Valorization of citrus by-products using Microwave Steam Distillation (MSD). Innovative Food Science and Emerging Technologies, 12(2), $163-170$.

Soottitantawat, A., Bigeard, F., Yoshii, H., Furuta, T., Ohkawara, M., \& Linko, P. (2005). Influence of emulsion and powder size on the stability of encapsulated Dlimonene by spray drying. Innovative Food Science and Emerging Technologies, 6(1), 107-114.

Soottitantawat, A., Yoshii, H., Furuta, T., Ohkawara, M., \& Linko, P. (2003). Microencapsulation by spray-drying: influence of emulsion size on the retention of volatile compounds. Journal of Food Science, 68(7), 2256-2262.

Soppimath, K. S., Kulkarni, A. R., \& Aminabhavi, T. M. (2001). Chemically modified polyacrylamide-g-guar gum-based crosslinked anionic microgels as $\mathrm{pH}$ sensitive drug delivery systems: preparation and characterization. Journal of Controlled Release, 75, 331-345.

Sosa-Herrera, M. G. Lozano-Esquivel, I. E., Ponce de León-Ramírez, Y. R., \& Martínez-Padilla, L. P. (2012). Effect of added calcium chloride on the physicochemical and rheological properties of aqueous mixtures of sodium caseinate sodium alginate and respective oil-in-water emulsions. Food Hydrocolloids, 29(1), 175-184.

Spectral Database for Organic Compounds, AIST (SDBS). http://sdbs.riodb.aist.go.jp/ sdbs/cgi-bin/direct_frame_top.cgi Accessed 20.03.13.

Stojanovic, R., Belščak-Cvitanovic, A., Manojlovic, V., Komes, D., Nedovic, V., \& Bugarski, B. (2012). Encapsulation of thyme (Thymus serpyllum L.) aqueous extract in calcium alginate beads. Journal of the Science of Food and Agriculture 92(3), 685-696.

Tabeei, A., Samimi, A., Khorram, M., \& Moghadam, H. (2012). Study pulsating electrospray of non-Newtonian and thixotropic sodium alginate solution. Journal of Electrostatics, 70, 77-82.

Uedo, N., Tatsuta, M., Iishi, H., Baba, M., Sakai, N., Yano, H., et al. (1999). Inhibition by d-limonene of gastric carcinogenesis induced by N-methyl- $\mathrm{N}^{\prime}$-nitro-N-nitrosoguanidine in Wistar rats. Cancer Letters, 137(2), 131-136. 
Vreeker, R., Li, L., Fang, Y., Appelqvist, I., \& Mendes, E. (2008). Drying and rehydration of calcium alginate gels. Food Biophysics, 3, 361-369.

Xie, J., Lim, K. L., Phua, Y., Hua, J., \& Wang, C. H. (2006). Electrohydrodynamic atomization for biodegradable polymeric particle production. Journal of Colloid and Interface Science, 302(1), 103-112.
You, J. O., Rafat, M., \& Auguste, D. T. (2011). Cross-linked heterogeneous colloidosomes exhibit pH-induced morphogenesis. Langmuir, 27(18), 11282-11286.

Zuidam, N. J., \& Heinrich, E. (2010). Encapsulation of aroma. In N. J. Zuidam, \& V. A. Nedovic (Eds.), Encapsulation Technologies for Active Food Ingredients and Food Processing. New York: Springer. 